\title{
PROPUESTA DE CONCEPTUALIZACIÓN DE LAS PERSONAS SORDAS E HIPOACÚSICAS EN EL CONTEXTO PEDAGÓGICO
}

\author{
Kenia Noguera Núñez, Elsie Pérez Serrano y Miguel Zaldívar Carrillo \\ .Instituto Superior Pedagógico "José de la Luz y Caballero", Cuba
}

\section{INTRODUCCIÓN}

Desde la era precristiana el hombre ha recorrido un largo y tortuoso camino para conocer acerca de los problemas sociales que implica la sordera. Muchos criterios se emplearon para nombrarlos o diferenciarlos e incluso se comparaban con los tontos , así "El código Justiniano(siglo VI) clasificaba a los sordos y mudos como mentalmente incompetentes y los rabinos del Talmud agrupaban a los sordos junto con los tontos y los niños (siglo II a.C.)". (PAPARELLA , 1983: 1265).

En esta época el niño que desarrollaba su lenguaje y vocabulario antes de ser instalada la sordera, era considerado hipoacúsico, aunque él no escuchaba las notas puras del lenguaje, cualquiera que fuese su intensidad. Se alegaba que las diferencias que se establecían con el sordo congénito, radicaban en que su lenguaje era relativamente "natural" o "normal".

Disímiles términos fueron empleados, los cuales no sólo sugerían factores fisiológicos, sobre la comunicación educativa, sino también, gradaciones del nivel de la audición y del momento de su comienzo, como fueron, sordomudo, mudo, sordo y mudo, sordo parcial, semisordo , semimudo, ensordecido, audimudos, sordastros, tartamudos, defectuosos de pronunciación ,entre otros.

Cabría preguntarse ¿qué se entiende por sordera, hipoacusia, trastorno auditivo y discapacidad?

Según Herrera C. "la sordera es la pérdida total de la audición o tal grado de disminución auditiva, que impida la comunicación verbal con ayuda del oído a aquellas personas que dominan el lenguaje oral en el momento de la pérdida auditiva", mientras que "la hipoacusia es la pérdida parcial de la audición que dificulta el desarrollo del lenguaje oral y su pleno dominio". (HERRERA , 1992: 10)

Una comisión especial de la conferencia de directores de Escuelas Norteamericanas para sordos, acordaron que sordo es "aquel que tiene un trastorno auditivo importante, que no puede procesar información lingüística por medio de la audición, utilice audífono o no". En el caso de la hipoacusia "es un individuo que por lo general merced al uso de un audífono, posee suficiente audición residual como para poder procesar bien la información lingüística por medio de la audición”.(PAPARELLA, 1983: 1266)

En el análisis de las terminologías antes mencionadas se alude a la conceptualización de trastorno auditivo, que se tuvo en cuenta para enunciar el mismo, concluyéndose que "es un término genérico que indica una incapacitación que puede variar desde leve hasta profunda; comprende los subgrupos sordos e hipoacúsicos". (HERRERA, 1992: 10)

Al interpretar estas definiciones surge la interrogante siguiente ¿es un sordo o un hipoacúsico, una persona discapacitada? 
En la Conferencia preparatoria del programa de atención a los discapacitados y desarrollo genético, efectuada en el mes de Noviembre del 2002 en la ciudad de Holguín, Cuba, se asumió que discapacidad es toda la limitación grave para realizar las actividades que tengan una persona siempre que su duración total sea superior a un año.

¿Querrá decir, que esta limitación grave por extenderse durante un tiempo extremadamente largo limitará la comunicación, el aprendizaje, las motivaciones, los intereses de los niños deficientes auditivos?.

Por supuesto que no, estos niños viven, crecen, se desarrollan, se integran y aman igual que un niño con capacidad auditiva normal. ¿Por qué entonces llamarlos discapacitados?

Otro término que ha revolucionado la educación, en particular la pedagogía especial, es el de las Necesidades Educativas Especiales (NEE). "Cambio conceptual establecido actualmente para la educación especial, que incluye a todos los educandos que por diversas causas presentan alguna dificultad para escalar nuevos estadios de desarrollo "(LÓPEZ, 2002: 44).

En él se incluye, no solo a aquellos niños con afectación del funcionamiento de uno o varios analizadores, sino también, a los niños con dificultades para aprender por cualquier causa, incluyendo la sobre dotación y el alto rendimiento escolar, pues todos necesitan de una respuesta pedagógica especial.

Como se puede apreciar la terminología empleada: sordo, hipoacusia, trastorno auditivo y discapacidad, centran su atención en el defecto, o sea en la causa clínica o el trastorno que se relaciona con las dificultades para aprender. En cuanto a la terminología Necesidades Educativas Especiales promueve la evolución de los niños, describiendo a partir de una detallada caracterización, sus dificultades y por qué se producen. Se describen además sus potencialidades para elaborar una estrategia educativa a desarrollar.

Otros términos son empleados en el proceso pedagógico (aunque no aparecen registrados en la literatura especializada), ellos son: niños con necesidades educativas especiales sensoriales, niños con necesidades educativas especiales por sordera.

Para adoptar una posición respecto al empleo de una terminología, es pertinente analizar elementos relacionados con la comunicación. Ya que "el niño sordomudo, aparentemente apartado del mundo, separado de todas las relaciones sociales, encontramos no la reducción sino el aumento del instinto social, de la voluntad para la vida social y del ansia de comunicación ".(VYGOTSKY, 1989: 33)

Teniendo en cuenta que para estos educandos es de vital importancia la comunicación para su desarrollo, se realizará el análisis de este concepto según diferentes autores (Tomado de CHERNOUSOVA, 2003: 20):

- González R, F.(1985) expresa que "la comunicación es un proceso esencial de toda la actividad humana, ya que se basa en la calidad de los sistemas interactivos en que el sujeto se desempeña y además tiene un papel fundamental en la atmósfera psicológica de todo grupo humano".

- $\quad$ Figueredo E. E. (1986) plantea que en "el proceso comunicativo el niño entra en contacto con lo que lo rodea, se relaciona con el mundo circundante, asimila nuevos conocimientos, se forma su pensamiento, de ahí que la primera función del lenguaje sea social". 
- Para Lomov B. F(1989), la comunicación es la interacción de las personas que entran en ella como sujeto(...). En ella se lleva a cabo un intercambio de actividades, presentaciones, ideas, orientaciones, intereses, se desarrolla y manifiesta el sistema de relaciones sujeto-objeto, necesitándose como mínimo para su realización, dos personas, cada una de las cuales actúa como sujeto.

- Para Maldonado A., Sebastián M. E y Soto (1999) consideran que la comunicación es un proceso donde un sistema transmite información a otro sistema que es capaz de recibirlo.

- Según (Chomsky , 1999) es un proceso mediante el cual un sistema transmite información a otro sistema que es capaz de recibirla.

De estas definiciones de desprende que independientemente de la forma y los medios empleados, la comunicación es un proceso de interacción que comprende los elementos siguientes (Figura 1):

- Emisor, Contenido, Canal, Receptor, Efecto.

Este proceso de comunicación entre las personas con pérdida auditiva, ocurre de la siguiente forma:

Figura 1.

Comunicación entre las personas con pérdida auditiva

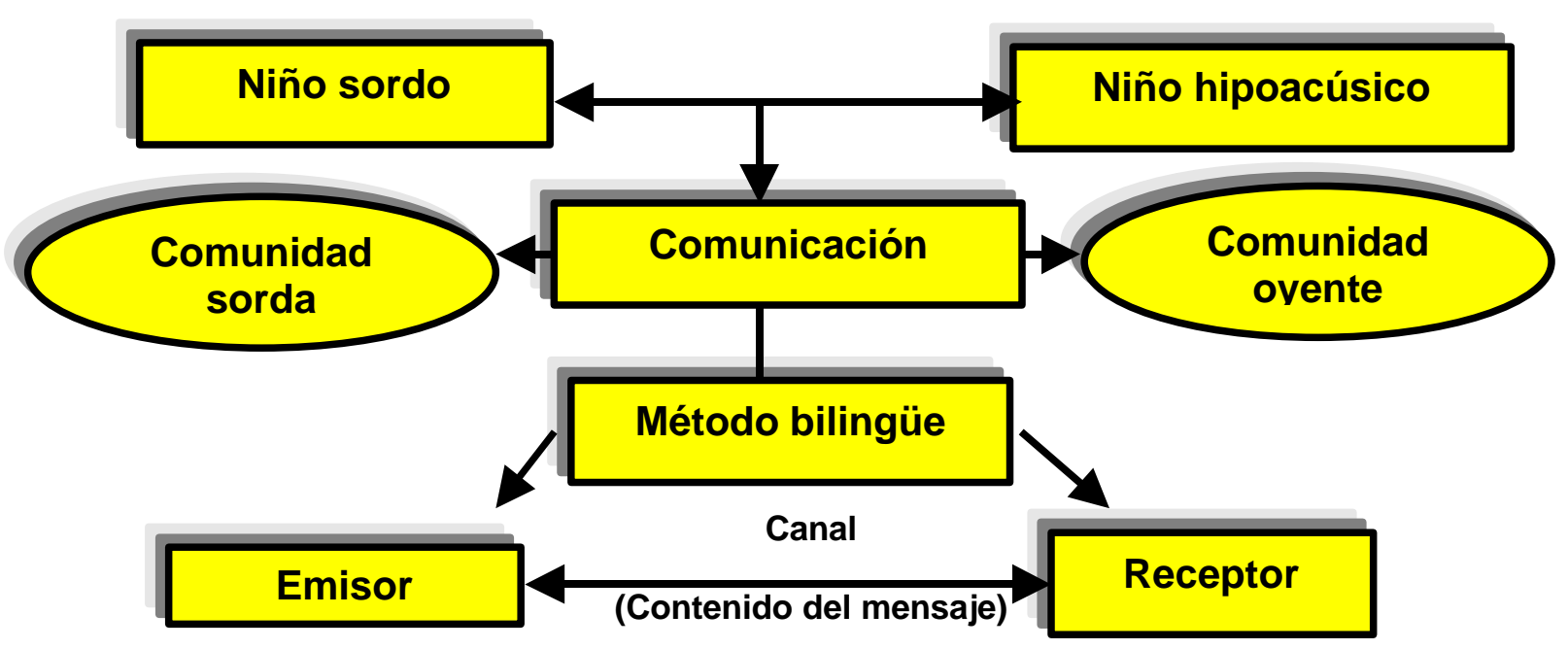

Teniendo en cuenta estos elementos sobre comunicación, se abordará la conceptualización pedagógica para las niñas y los niños con deficiencia auditiva . Una comisión multidisciplinaria dirigida por Warnock M. (1974) valoró cuan agresivos constituyen los términos que se empleaban para denominar las personas privadas de una capacidad o de un analizador.

Según el Informe Warnock (1978) los niños con Necesidades Educativas Especiales requieren de tres exigencias:

- Dotación de medios especiales de acceso al currículo mediante equipamiento o de recursos especiales, la modificación del medio físico o técnicas de enseñanza especializadas.

- Dotación de un currículo especial o adaptado. 
- Necesidad de una particular atención a la estructura social y al clima emocional en los que tiene lugar la educación.

En esta reunión se acordó que a escala internacional se debían humanizar los términos o conceptos manejados a través de la historia, vinculando los mismos al proceso educativo y no tomando como base el defecto.

En 1994 se efectúa en Salamanca la Conferencia Mundial sobre Necesidades Educativas Especiales: acceso y calidad, en la cual se realiza un análisis minucioso sobre los retos que enfrenta la educación mundial. De lo que se trata de conseguir es una educación de calidad para todos, una escuela en la que se garantice el desarrollo integral de todos los alumnos, incluyendo las niñas y niños con necesidades educativas especiales, teniendo en cuenta sus características personales y los de su entorno cultural.

Considerando estos nuevos postulados, las diferentes especializaciones que conforman la educación especial, han dado pasos importantes para abordar, desde un enfoque netamente pedagógico, las dificultades para aprender de estas personas. En relación con ello, surge la necesidad de emplear una denominación que responda a las necesidades de estos estudiantes, sin obviar los aspectos clínicos que subyacen en la base de sus necesidades y potencialidades.

Para los pedagogos resulta más importante no el déficit, sino las potencialidades de desarrollo que cada persona posee. Si embargo es oportuno tener en cuenta el defecto primario, que en este caso es la pérdida o deterioro de la audición, los residuales aprovechables que posee y el grado de afectación de la comunicación con sus semejantes. Se tiene que analizar no solo este contexto de comunicación, sino aquel en que se establece con la comunidad oyente, que es en definitiva a la cual se integrara en etapas posteriores.

Si se analiza las terminologías tradicionalmente utilizadas para denominar a las personas con pérdidas total o parcial de la capacidad auditiva hay que significar que tanto para unos como para otros las respuestas educativas son diferentes tanto en los métodos a utilizar como en los objetivos que debe emplear el educador. De ahí que la denominación que se utilice en la práctica educativa debe ir dirigida hacia el diagnóstico diferencial que permita establecer las respuestas pedagógicas para lograr un accionar educativo dirigido fundamentalmente a la compensación auditiva y el entrenamiento acústicos de los restos conservados.

Después de analizar estas definiciones se ha considerado que el término actual, para denominar los niños con una pérdida parcial o total de la audición, no responde a las verdaderas necesidades pedagógicas y psicológicas que demandan. La principal necesidad que ellos tienen se encuentra en la comunicación entre si, con sus maestros y con la comunidad en la que se desarrollan. De igual forma deben aprender a utilizar convenientemente el residual auditivo que poseen. Precisamente estas limitaciones en la comunicación son las que originan sus dificultades para aprender, o sea la inadecuación de la respuesta pedagógica a ellas. Esto produciría un déficit de experiencias y de transmisión de información al niño que puede retrasarlo en aspectos importantes de su desarrollo.

Considerando que estos educandos, más que tener una necesidad auditiva, tienen la necesidad de que se empleen medios adecuados para comunicarse y entrenar sus restos auditivos de manera que les permita desarrollar sus habilidades comunicativas y un mejor aprendizaje, en este trabajo se hace una 
propuesta de denominación en los siguientes términos: Necesidades Educativas Especiales comunicativas (NEEC).

Las personas con NEEC son todas aquellas que por el grado de pérdida auditiva presentan limitaciones en la estructuración y funcionamiento de las diferentes dimensiones de la competencia comunicativa .

Dentro de estas necesidades se incluye un primer grupo: Necesidades Educativas Especiales en Entrenamiento Auditivo: aquellos niños a los que el grado de perdida auditiva les permite discriminar acústicamente sonidos fuertes y necesitan de un entrenamiento auditivo a través de la percepción de sonidos del lenguaje oral.

¿Cómo ubicar un subgrupo que incluya a las personas con pérdidas significativas en la capacidad auditiva?

Para dar respuesta a esta interrogante el análisis se dirige hacia la Lingüística y en particular al término código lingüístico. Este término fue introducido recientemente en la lingüística y es considerado sinónimo de sistema de signos.(Temas lingüísticos , Pág. 14)

Según Voinova A.(1989): Los signos lingüísticos se relacionan con los actos de comprensión e interpretación semántica de los signos en el proceso de comunicación. (Pág. 25)

Muchas formas han servido para definir los códigos lingüísticos:

- Son sustituciones de los conceptos, de las ideas .

- Son señales que cumplen función comunicativa.

- Es la relación entre el significante y el objeto designado ,o sea, la relación objetiva.

- Es la relación entre el signo y la actividad del hombre(comprensión operacional del significado).

- Constituye la relación entre el hablante y el oyente. En este caso, el significado se determina en forma de estimulo - reacción. (Voinova A. Pág. 30)

Los códigos lingüísticos poseen determinados rasgos que al analizarlos se interrelacionan con los diferentes métodos comunicativos utilizados por las personas con las NEE anteriormente analizadas, los que a continuación serán enunciados:

1) Deben ser percibidos por los sentidos humanos(carácter material).

2) Carácter arbitrario.

3) Aprobación de la colectividad que los utiliza (función social).(El método bilingüe se encuentra aprobada por la Asociación Nacional de Sordos de Cuba :ANSOC).

4) Obligatoriedad del signo en relación con el sistema del cual forma parte.(El método bilingüe se utiliza en todas las instituciones educacionales donde son educadas las personas con estas necesidades educativas, de igual forma se utilizada en todas las actividades tanto de la ANSOC como en aquellas en que esté presente una persona con determinada pérdida en la capacidad auditiva y que requiere de un interprete en lengua de señas para poder recibir información así como transmitirla. 
Para las personas con pérdida total en la capacidad auditiva el desarrollo en códigos lingüísticos les permitirán comunicar y pensar, oral o manual, de ahí la importancia de desarrollar a través de la palabra los códigos lingüísticos respetando siempre su identidad y su forma de comunicación.

Por lo cual se considera pertinente analizar la conceptualización que abarca a este subgrupo anteriormente explicado: Necesidades Educativas Especiales en Códigos Lingüísticos (NEE CL.).

NEE CL: aquellas personas que teniendo en cuenta el grado de pérdida de la capacidad auditiva necesitan de códigos lingüísticos que les permitan comunicar y pensar ya sea oral o manual .

Las Necesidades Educativas Especiales Comunicativas se establecen tanto para las personas con pérdida total como parcial en la capacidad auditiva se conceptualizan los primeros como Necesidades Educativas Especiales en Códigos Lingüísticos y los segundos como Necesidades Educativas Especiales en Entrenamiento Auditivo (fig. 2). En ambos casos estas necesidades requieren tres exigencias:

1) Recursos especiales.

2) Currículo adaptado .

3) Atención a la estructura social y al clima emocional.

En las Necesidades Educativas Especiales en Códigos Lingüísticos mediante el bilingüismo se le desarrollara y/o compensara los componentes léxico, fónico y gramatical y en las Necesidades Educativas Especiales en Entrenamiento Auditivo utilizaría el lenguaje oral para la percepción acústica de los sonidos del lenguaje hablado y el desarrollo del componente fónico ( voz, respiración, pronunciación).

En ambas necesidades se cumplirán los objetivos siguientes:

1) Desarrollo de la comunicación y el pensamiento.

2) Adecuación de respuestas pedagógicas en función del diagnóstico.

3) Intervención temprana en la educación acústica y lingüística.

4) Experiencias socio emocionales con la comunidad en que se desarrolla.

5) Desarrollo de su personalidad.

Con el conocimiento y el accionar de los educadores estas personas pueden lograr una integración educativa eficiente, con la utilización idónea de recursos auditivos, mejoradas las condiciones acústicas del entorno que permiten llegar la información pertinente, así como el uso adecuados de métodos sensoperceptuales con canal de comunicación en el caso de perdidas profundas.(Fig. 2)

Como se aprecia la terminología propuesta deja de tener en su centro los conceptos clínicos que refuercen el defecto, para convertirse en términos que ocupan a la pedagogía actual. Se describe el tipo de recursos que demandan estos niños y que desencadena un sistema de estrategias que dé solución a sus necesidades y permita contribuir al alcance de los objetivos trazados por el sistema educativo nacional: lograr una educación cada vez superior. 
Figura 2.

Necesidades educativas especiales comunicativas.

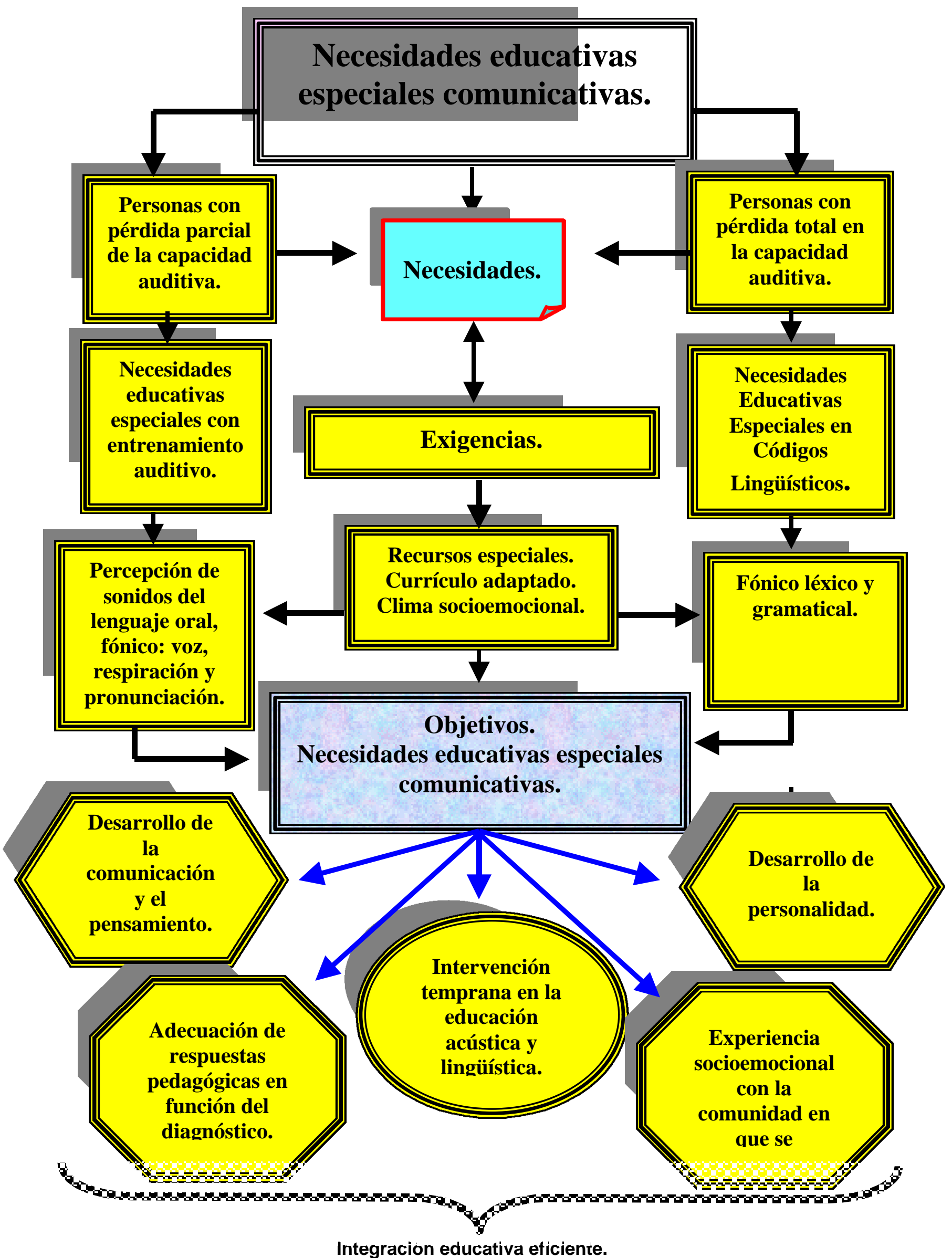

Integracion educativa eticiente. 


\section{CONCLUSIONES}

- Resulta imprescindible adentrarnos en una etapa de reconceptualización de los conceptos con los que hemos enfrentado el estudio de los niños con necesidades educativas especiales en general y los sordos en particular, dado que recaemos, con bastante frecuencia, en posiciones excluyentes y discriminatorias, originadas por la falta de sensibilidad encarnada en las anteriores denominaciones.

- Se proponen los conceptos de: Necesidades Educativas Especiales Comunicativas, Necesidades Educativas Especiales en códigos lingüísticos y Necesidades Educativas Especiales en Entrenamiento Auditivo, dependiendo de los tipos y grados de pérdida auditiva.

\section{BIBLIOGRAFÍA}

Chernosova, Liuba. (2003). Las Necesidades Educativas Especiales en escolares con trastornos severos en la comunicación. Estudios avanzados. Cienfuegos: Girona.

Colectivo de Autores. (2002). Convocados por la diversidad. La Habana: Pueblo y Educación.

Colectivo de Autores. (1999). Educación Especial e integración escolar y social en Cuba(1). Madrid: Aljibe.

Figueredo, Ernesto. (2000). Fundamentos psicológicos del lenguaje. Santiago de Chile: Instituto de investigaciones y perfeccionamiento e innovaciones internacionales.

FigueREDO, Ernesto. (1997). Experiencia cubana en la atención a sujetos con trastornos severos del lenguaje. La Habana: Curso taller Pedagogía 97.

HerRera, Cándida. (1992) ¿Tu hijo oye bien? La Habana: Pueblo y educación.

Paparella, Michel. (1983). Otorrinolaringología. Ciencias básicas y disciplinas afines. La Habana: Científico- Técnica.

VIGOTSKY, Lev. (1989). Obras Completas- tomo 5. La Habana: Pueblo y Educación.

VoInova, A. (1985). Curso de Lingüística. La Habana: Editorial Pueblo y Educación. 


\title{
Contactar
}

Revista lberoamericana de Educación

\author{
Principal OEI
}

